OPEN ACCESS

Edited by:

Feng Wang,

City University of Hong Kong,

Hong Kong

Reviewed by:

Xiaoji Xie,

Nanjing Tech University, China

Wei Zhang,

Sichuan University, China

Kristiina Oksman,

Luleå University of

Technology, Sweden

*Correspondence:

Takayuki Hirano

takayuki_hirano@trc.toray.co.jp

Tsuguyuki Saito

asaitot@mail.ecc.u-tokyo.ac.jp

Specialty section:

This article was submitted to

Nanoscience,

a section of the journal

Frontiers in Chemistry

Received: 14 October 2019

Accepted: 21 January 2020

Published: 07 February 2020

Citation:

Hirano T, Mitsuzawa K, Ishioka S,

Daicho K, Soeta H, Zhao M,

Takeda M, Takai Y, Fujisawa S and

Saito T (2020) Anisotropic Thermal

Expansion of Transparent Cellulose

Nanopapers. Front. Chem. 8:68.

doi: 10.3389/fchem.2020.00068

\section{Anisotropic Thermal Expansion of Transparent Cellulose Nanopapers}

\author{
Takayuki Hirano ${ }^{1 *}$, Kana Mitsuzawa ${ }^{1}$, Shun Ishioka ${ }^{2}, K^{2}$ azuho Daicho ${ }^{2}$, Hiroto Soeta ${ }^{2}$, \\ Mengchen Zhao ${ }^{2}$, Masaaki Takeda ${ }^{1}$, Yoshihiro Takai ${ }^{1}$, Shuji Fujisawa ${ }^{2}$ and \\ Tsuguyuki Saito ${ }^{2 *}$ \\ ${ }^{1}$ Material Characterization Laboratories, Toray Research Center, Otsu, Japan, ${ }^{2}$ Department of Biomaterial Sciences, \\ Graduate School of Agricultural and Life Sciences, The University of Tokyo, Tokyo, Japan
}

We report the anisotropic thermal expansion of a transparent nanopaper structure comprising cellulose nanofibers (CNFs). The coefficient of thermal expansion (CTE) of the nanopaper in the out-of-plane direction was $44.6 \mathrm{ppm} /{ }^{\circ} \mathrm{C}$ in the temperature range of $25-100^{\circ} \mathrm{C}$, which is approximately five times larger than its CTE in the in-plane direction in the same temperature range $\left(8.3 \mathrm{ppm} /{ }^{\circ} \mathrm{C}\right)$. Such a strong anisotropy in thermal expansion is mainly attributable to the anisotropic CTE values of single CNFs in the fiber axis and cross-sectional directions. We observed anisotropic thermal expansion even in a bioplastic composite containing only $2.5 \% \mathrm{w} / \mathrm{w}$ CNFs.

Keywords: cellulose nanofiber, thermal expansion, anisotropy, film, nanopaper

\section{INTRODUCTION}

Cellulose nanofibers (CNFs) are high-performance biobased materials with high mechanical strength and low thermal expansion. They are produced as water dispersions and can be formed into films. The production of CNF dispersions and films is well-established, and their uses are now being explored. CNF films are often called "nanocellulose paper" or simply "nanopaper" (Henriksson et al., 2008; Zhao et al., 2018), because they are made from nanometer-wide fibers and form paper-like network structure at the nanoscale. Some transparent grades of the nanopapers are even called "transparent paper" (Nogi et al., 2009). The nanopaper structure can exploit the potential of CNFs, and combine mechanically and thermally superior properties.

A promising application of nanopapers is their use as flexible substrates in electronic devices (Nogi et al., 2009). In recent years, electronic devices have become smaller and thinner, and are often required to fit into very limited spaces. In such cases, it is important to reduce any thermal stress on the substrates. Therefore, substrates need high dimensional stability and favorable radiation performance. Single CNFs are thermally anisotropic. The thermal conductivity of nanopapers is significantly higher in the in-plane direction than in the out-of-plane direction (Diaz et al., 2014; Uetani et al., 2015). Such anisotropic conductivity could enable the design of new heat management for electronic devices (Uetani et al., 2017). The nanopapers also have a low coefficient of thermal expansion (CTE) in the in-plane direction (Nogi et al., 2009; Diaz et al., 2013), which makes them particularly useful as substrates. However, to the best of our knowledge the CTE of the nanopapers in the out-of-plane direction has not yet been reported.

Herein, we demonstrate the anisotropy in thermal expansion of transparent nanopapers. The nanopapers were prepared from a 2,2,6,6-tetramethylpiperidin-1-oxyl (TEMPO)-oxidized CNF/water dispersion (Zhao et al., 2018). The in-plane and out-of-plane CTE values of the nanopapers were determined by thermomechanical analysis (TMA) and laser interferometry, respectively. For reference, two other cellulosic films were assessed in the same manner: one was 
a bioplastic film of cellulose acetate (CA), and the other was a composite film with a CA matrix containing $2.5 \% \mathrm{w} / \mathrm{w}$ TEMPOoxidized CNFs.

\section{MATERIALS AND METHODS}

\section{Materials}

A $0.4 \%$ w/w TEMPO-oxidized CNF/water dispersion was prepared according to the method described in a previous report (Zhao et al., 2018). The carboxylate content, weighted-average length and width of the CNF sample were $\sim 1.2 \mathrm{mmol} / \mathrm{g}, 1 \mu \mathrm{m}$, and $3 \mathrm{~nm}$, respectively. The $\mathrm{CNF}$ dispersion $(80 \mathrm{~mL})$ was poured into a $90-\mathrm{mm}$-diameter polystyrene petri dish and dried at rest in an oven at $40^{\circ} \mathrm{C}$ for 1 week. The resulting nanopaper was peeled from the petri dish and then conditioned at $23^{\circ} \mathrm{C}$ and $50 \%$ relative humidity for more than 2 days. The CA (LT-35) was supplied by Daicel Corp., Tokyo, Japan. The degrees of polymerization and substitution of the CA are 270 and 2.87, respectively, according to the data catalog. A $2 \% \mathrm{w} / \mathrm{w}$ CA solution was prepared using $N$, $\mathrm{N}$-dimethylacetamide (DMAc) as the solvent. The CA solution $(25 \mathrm{~mL})$ was poured into a $90-\mathrm{mm}$-diameter glass petri dish and dried at rest in vacuo at $40^{\circ} \mathrm{C}$ for 1 day and subsequently at $70^{\circ} \mathrm{C}$ for 1 week. The $\mathrm{CA} / \mathrm{CNF}$ composite was prepared from a mixture of the CA solution $(25 \mathrm{~mL})$ and a $0.1 \% \mathrm{w} / \mathrm{w}$ TEMPO-oxidized CNF/DMAc dispersion $(12 \mathrm{~mL})$, according to the method described in a previous report (Soeta et al., 2017). The mixture $(12 \mathrm{~mL})$ was dried under the same conditions as for the CA film. The dried films of the CA and CA/CNF composite were peeled from the petri dishes and conditioned as well as the nanopaper.

\section{TMA}

The TMA was performed using a Shimadzu TMA-50 system in a nitrogen atmosphere within a temperature range of $\sim 25-120^{\circ} \mathrm{C}$ at a heating rate of $2^{\circ} \mathrm{C} / \mathrm{min}$. Before analysis, the film specimens (plane size $12 \mathrm{~mm} \times 10 \mathrm{~mm}$ ) were dried at $130^{\circ} \mathrm{C}$ in the device. The specimens were positioned vertically, and the dimensional changes in the in-plane direction were measured under a slight compression load $(5 \mathrm{mN})$ on the cross-sections of the specimens.

\section{Laser Interferometry}

The laser interferometry was performed using an Advance Riko LIX-2 system in a helium atmosphere at $\sim 90 \mathrm{kPa}$ under the same thermal conditions used for the TMA. The specimens (plane size $7 \mathrm{~mm} \times 7 \mathrm{~mm}$ ) were positioned horizontally, and their dimensional changes in the out-of-plane direction were measured under a slight compression load $(167 \mathrm{mN} ; 6 \mathrm{kPa})$ on the surfaces of the specimens.

\section{Scanning Electron Microscopy (SEM)}

A rectangular specimen $3 \mathrm{~mm} \times 30 \mathrm{~mm}$ in size was cut out from a nanopaper. The specimen was fractured by uniaxial tensile load using a Shimadzu EZ-SX at $23^{\circ} \mathrm{C}$ and $50 \%$ relative humidity. The gauge length and head speed were set to $10 \mathrm{~mm}$ and 1 $\mathrm{mm} / \mathrm{min}$, respectively. The fractured surface was treated using a Meiwafosis Neoc osmium coater at $6 \mathrm{~mA}$ for $2.5 \mathrm{~s}$. The osmiumtreated surface was observed by SEM using a Hitachi S-4800 at $1.5 \mathrm{kV}$.

\section{Raman Spectroscopy}

Raman spectroscopy was carried out using a customized Photon Design near-infrared Raman spectrometer equipped with a YAG laser (wavelength 1,064 nm) and a Nippon Roper InGaAs detector. The intensities of the Raman band at $1,100 \mathrm{~cm}^{-1}$ (glycoside bond) were recorded as a function of the rotational angle of the polarization, as reported previously (Wanasekara et al., 2016).

\section{RESULTS AND DISCUSSION}

The nanopapers were prepared through evaporative condensation of a TEMPO-oxidized CNF/water dispersion. The TEMPO-oxidized CNFs are spontaneously arranged into a polydomain nematic order on the condensation process, such that a plywood-like nanostructure of the densified nematic-CNF arrangement is finally formed in the dried nanopapers. [See a reference by Zhao et al. (2018) for details of the nematic ordering.] The nanopapers were $\sim 30-\mu \mathrm{m}$ thick, and were optically transparent. The reference films of the CA and $\mathrm{CA} / \mathrm{CNF}$ composite were prepared through solvent casting in vacuo, according to the method described in a previous report. In the composite, TEMPO-oxidized CNFs are homogeneously distributed at the ratio of $2.5 \% \mathrm{w} / \mathrm{w}$ and form a percolating network in the CA matrix. [See a reference by (Soeta et al., 2018) for details of the composite structure]. Both the CA-based films were $\sim 80-\mu \mathrm{m}$ thick, and were optically transparent as well as the nanopapers (Soeta et al., 2017).

Figure 1 shows the thermal expansivity $\Delta L / L_{0}$ of the nanopaper and CA-based films in the in-plane and out-of-plane directions, where $L_{0}$ is the initial length or thickness of the specimen at $\sim 25^{\circ} \mathrm{C}$, and $\Delta L$ is the change in the corresponding dimension of the specimen following thermal expansion. The four measurements for each type are displayed in the figure and show the high reproducibility. The temperature dependency of the thermal expansivity was approximately linear in the temperature range $\Delta T$ of $25-100^{\circ} \mathrm{C}$ for all three types of specimen in both the in-plane and out-of-plane directions. At the temperature of $\sim 100^{\circ} \mathrm{C}$, only the expansivity of the nanopaper in the out-of-plane direction somehow showed an infection point, and became nearly flat in the higher $\Delta T$ of $100-120^{\circ} \mathrm{C}$. This is perhaps related to the specific thermal expansion of wood cellulose crystallites; Hori and Wada (2005) observed that the hydrogen bonding sheet significantly shrank along the $b$-axis of the unit cell $\left(-30 \mathrm{ppm} /{ }^{\circ} \mathrm{C}\right)$ although the sheet stacking distance of the $a$-axis expanded $\left(136 \mathrm{ppm} /{ }^{\circ} \mathrm{C}\right)$. This interpretation should be based on the orientation of crystallites to the out-of-plane direction, which is described in the latter part of this paper. Note that not only CNFs but also the CA have no glass transition and melting points in the whole $\Delta T$ of $25-120^{\circ} \mathrm{C}$ (Soeta et al., 2018)

The CTE values were calculated from the linear regions in the $\Delta T$ of $25-100^{\circ} \mathrm{C}$ using the following equation:

$$
\bar{a}=\frac{1}{L_{0}} \cdot \frac{\Delta L}{\Delta T}
$$

The values are shown in Table $\mathbf{1}$ as the mean and standard deviation of the four measurements in Figure 1. The CTE of the 

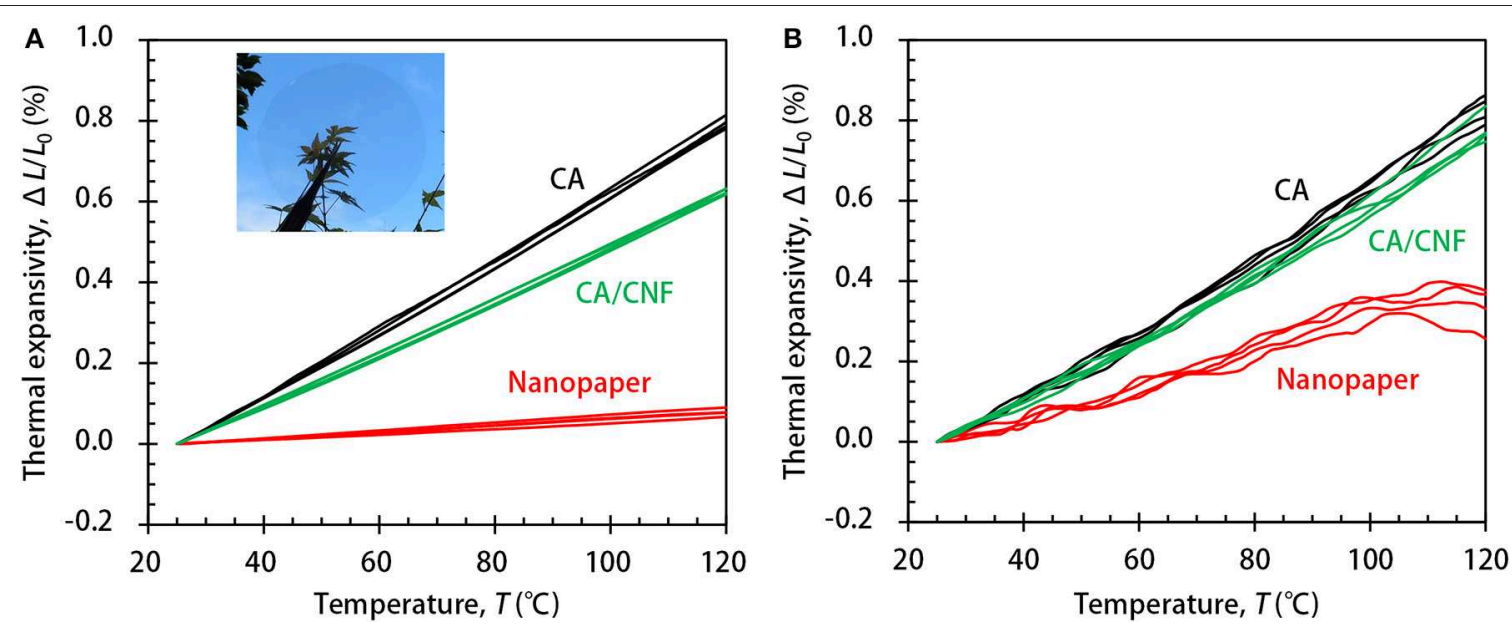

FIGURE 1 | The thermal expansivity of the nanopaper and CA-based films in the (A) in-plane and (B) out-of-plane directions. The inset in (A) illustrates the optical transparency of the nanopaper.

TABLE 1 | The in-plane and out-of-plane CTE values of the nanopaper and CA-based films in the temperature range of $25-100^{\circ} \mathrm{C}$.

\begin{tabular}{lcc}
\hline Sample & \multicolumn{2}{c}{ CTE (ppm/ $\left.{ }^{\circ} \mathbf{C}\right)$} \\
\cline { 2 - 3 } & In-plane & Out-of-plane \\
\hline Nanopaper & $8.3 \pm 1.2$ & $44.6 \pm 3.7$ \\
CA & $82.5 \pm 1.7$ & $84.5 \pm 2.2$ \\
CA/CNF & $65.1 \pm 1.0$ & $78.0 \pm 3.0$ \\
\hline
\end{tabular}

nanopaper in the in-plane direction was as low as $8.3 \mathrm{ppm} /{ }^{\circ} \mathrm{C}$, which is comparable to that of a glass, as previously reported (Nogi et al., 2009). In contrast, the CTE in the out-of-plane direction was significantly higher $\left(44.6 \mathrm{ppm} /{ }^{\circ} \mathrm{C}\right)$. A CTE of 44.6 $\mathrm{ppm} /{ }^{\circ} \mathrm{C}$ is still as low as that of a polymeric solid, but some grades of plastics have similar or even lower CTE values. The reference CA film was thermally isotropic as predicted, and its CTE values in the in-plane and out-of-plane directions were both $\sim 80 \mathrm{ppm} /{ }^{\circ} \mathrm{C}$. Whereas, the out-of-plane CTE of the CA/CNF composite was also $\sim 80 \mathrm{ppm} /{ }^{\circ} \mathrm{C}$, it is significant that its in-plane CTE value was lower $\left(65.1 \mathrm{ppm} /{ }^{\circ} \mathrm{C}\right)$.

Note that the in-plane and out-of-plane CTE values of the specimens were determined by TMA and laser interferometry, respectively. The $\Delta L$ resolutions for TMA and laser interferometry are $\sim 100$ and $2 \mathrm{~nm}$, respectively; in fact, the measurements were performed in the detectable ranges. For instance, the lower limit of the out-of-plane CTE value of the nanopaper is estimated to be $\sim 0.9 \mathrm{ppm} /{ }^{\circ} \mathrm{C}$ using the $L_{0}$ and $\Delta T$ values of $30 \mu \mathrm{m}$ and $75^{\circ} \mathrm{C}\left(25-100^{\circ} \mathrm{C}\right)$, respectively, which is sufficiently lower than the experimental value of $44.6 \mathrm{ppm} /{ }^{\circ} \mathrm{C}$.

It is interesting that the thermal expansion of transparent nanopapers was strongly anisotropic $(\sim 8: 45)$. This phenomenon can be interpreted based on the thermal anisotropy of single CNFs (equal to the crystallites in structural meaning). The thermal expansion of individual CNFs in the fiber axis direction is strongly restrained by covalent bonds. The CTE of such fibers is estimated to be $6 \mathrm{ppm} /{ }^{\circ} \mathrm{C}$ in the case of wood cellulose (Hori and Wada, 2005). In contrast, the cross-sectional expansion of individual CNFs is governed by intermolecular interactions. The area CTE of the fiber cross-section is estimated to be $106 \mathrm{ppm} /{ }^{\circ} \mathrm{C}$ based on the data by Hori and Wada (2005). Thus, the mean linear CTE in the cross-sectional directions is calculated to be 53 $\mathrm{ppm} /{ }^{\circ} \mathrm{C}$, and is much larger than the axial CTE of $6 \mathrm{ppm} /{ }^{\circ} \mathrm{C}$. The contribution of such thermal anisotropy of CNFs to the nanopaper expansion is realized by analysis of the nanopaper structure (see Figure 2).

Figure 2 shows how CNFs are packed in the nanopaper. The structure of nanopapers has multi-layered anisotropy (Figure 2a), and CNFs are packed approximately parallel to the in-plane direction of each layer (Figure 2b). This structure is supported by Raman spectroscopy for the fiber axis of CNFs (glycoside bond) in the nanopaper (Figure 2c). Also, such laid CNFs are isotopically stacked up to the out-of-plane direction (Figure 2d). XRD and FTIR analyses of the nanopaper are shown in Supplementary Figures S1, S2, respectively. [See also a reference by (Zhao et al., 2018) for nanopaper structure]. It is therefore reasonable to interpret the data in Table $\mathbf{1}$ as meaning that the CTE values of the nanopapers in the in-plane and outof-plane directions mainly arise from those of individual CNFs in the fiber axis and cross-sectional directions, respectively. The anisotropy of the CA/CNF composite ( 65:78) also suggests that the fiber axes of the CNFs in the CA matrix were on average perpendicular to the out-of-plane direction.

A similar anisotropy has been reported for the in-plane thermal expansion of uniaxially oriented cellulose nanocrystal (CNC) films (Diaz et al., 2013). The in-plane CTE values of the CNC films in the two directions parallel and perpendicular to the orientation axis are $\sim 9$ and $158 \mathrm{ppm} /{ }^{\circ} \mathrm{C}$, respectively. The large in-plane $\mathrm{CTE}$ of $158 \mathrm{ppm} /{ }^{\circ} \mathrm{C}$ has been interpreted as the result including not only the cross-sectional expansion of crystallites but also the contribution of inter-crystallite (CNC-CNC) interfacial motion. However, the out-of-plane CTE 

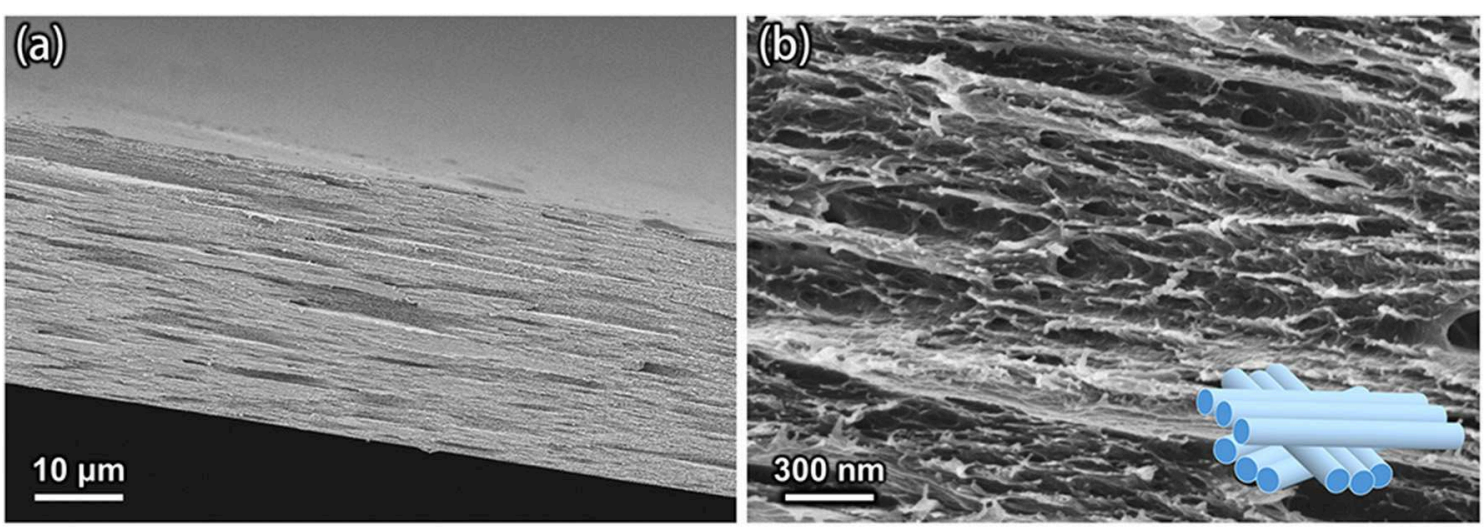

(c)

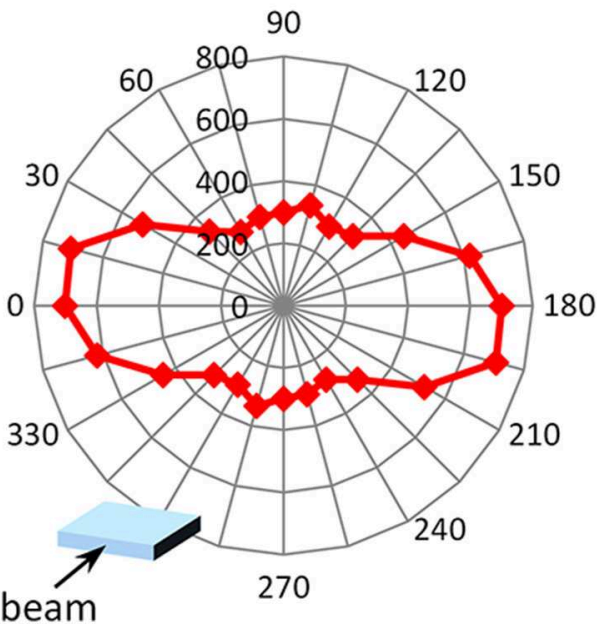

(d)

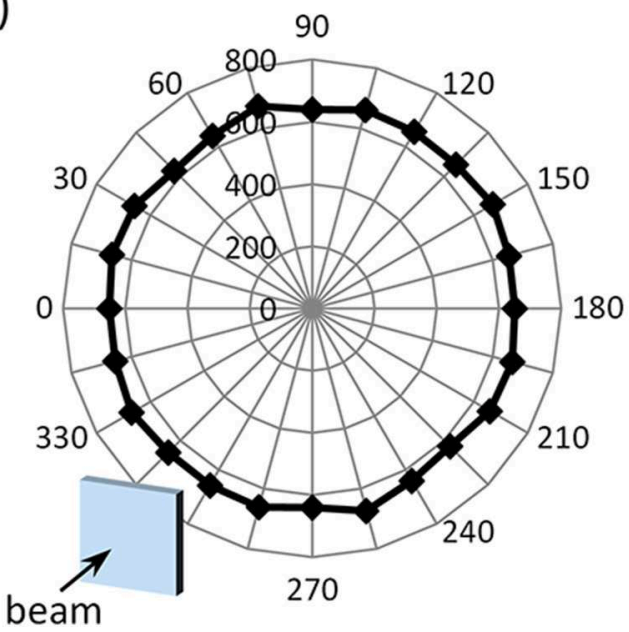

FIGURE 2 | Structure of the nanopaper. (a,b) SEM images of a cross section of the nanopaper. The inset in the (b) shows a simplified model for the packing structure of CNFs. (c,d) Polar plots of the normalized intensities of the Raman band at 1,100 $\mathrm{cm}^{-1}$ (glycoside bond), recorded by applying the laser beam to (c) the cross-section and (d) the surface of the nanopaper.

of our nanopapers $\left(44.6 \mathrm{ppm} /{ }^{\circ} \mathrm{C}\right)$ can only be explained by the cross-sectional expansion of crystallites $\left(53 \mathrm{ppm} /{ }^{\circ} \mathrm{C}\right)$. This result indicates that the inter-CNF interactions are dominated by hydrogen bonding; as discussed above, the CTE of the hydrogen bonding sheet along the $b$-axis of the unit cell is nearly zero (Wada, 2002) or even negative (Hori and Wada, 2005), whereas the CTE of the hydrophobic sheet-stacking in the $a$-axis direction is as large as $43-136 \mathrm{ppm} /{ }^{\circ} \mathrm{C}$. Note that $\mathrm{XRD}$ profiles of woodderived CNC films and nanopapers show no orientation of the crystal planes to the film surface (Elazzouzi-Hafraoui et al., 2008; Daicho et al., 2018).

Figure 3 summarizes our interpretation for the anisotropic nanopaper expansion. In the temperature range of $25-100^{\circ} \mathrm{C}$, the out-of-plane CTE value $\left(44.6 \mathrm{ppm} /{ }^{\circ} \mathrm{C}\right)$ was found to be larger than the in-plane value $\left(8.3 \mathrm{ppm} /{ }^{\circ} \mathrm{C}\right)$; however, it should be noted that actual dimensional change in the out-of-plane direction for a thin nanopaper with a thickness of $30 \mu \mathrm{m}$ is only $0.1 \mu \mathrm{m}$ and is indeed much smaller than its in-plane change $(6.2 \mu \mathrm{m}$ on a side for a square $10 \mathrm{~mm} \times 10 \mathrm{~mm}$; Figures 3A,B). A similar remark holds for single CNFs (Figures 3C,D); the dimensional change in the cross-sectional direction for a single CNF with a diameter of
$3 \mathrm{~nm}$ is estimated to be only $0.012 \mathrm{~nm}$ on average, which is much smaller than its length change $(0.23 \mathrm{~nm}$ for a length $500 \mathrm{~nm})$. The anisotropic CTE of nanopapers will be thus pronounced as actual dimensional changes for thick or laminated nanopapers. It is also worth mentioning that the dimensional change in the outof-plane direction $(\sim 0.1 \mu \mathrm{m})$ is sufficiently larger than reported values of the root-mean surface roughness $(\sim 6-10 \mathrm{~nm})$ for the nanopapers of TEMPO-oxidized CNFs prepared in the same manner as this work (Wu et al., 2014; Zhao et al., 2018).

\section{CONCLUSIONS}

In the present study, we demonstrated the anisotropic thermal expansion of transparent nanopaper structures comprising CNFs. The out-of-plane CTE value of the nanopaper was approximately five times larger than the in-plane value (44.6 $\mathrm{ppm} /{ }^{\circ} \mathrm{C}$ vs. $8.3 \mathrm{ppm} /{ }^{\circ} \mathrm{C}$, respectively). Such a strong anisotropy in thermal expansion was mainly attributable to the anisotropic CTE values of single CNFs in the fiber axis and cross-sectional directions. It is interesting that a transparent polymeric solid 

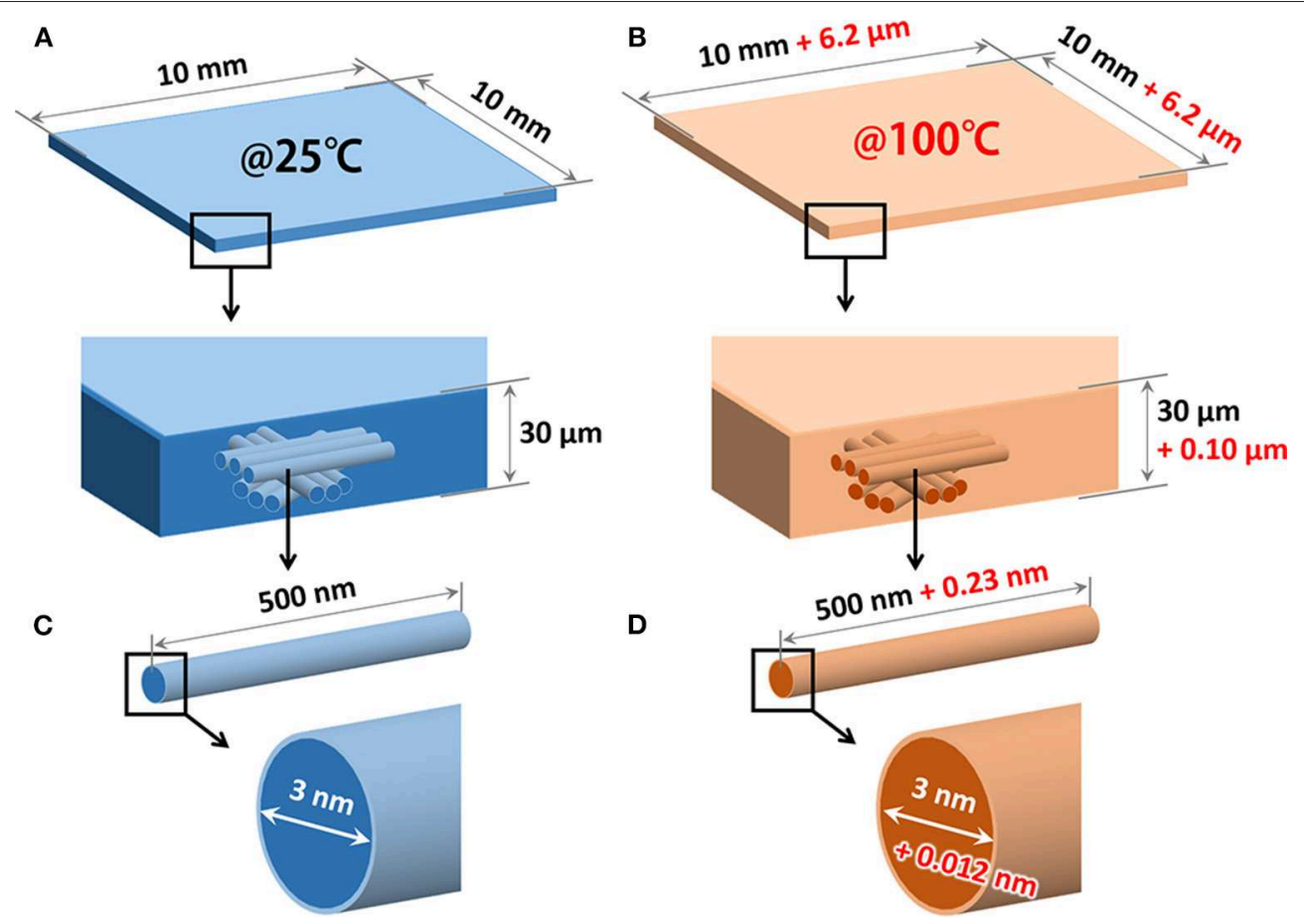

FIGURE 3 | Association of the nanopaper expansion with thermal anisotropy of single CNFs. (A,B) Thermal expansion of a nanopaper specimen with dimensions of $10 \mathrm{~mm} \times 10 \mathrm{~mm} \times 30 \mu \mathrm{m}$ in the temperature range of $25-100^{\circ} \mathrm{C}$. The dimensional changes at $100^{\circ} \mathrm{C}$ (the values in red) are calculated using the $\mathrm{CTE}$ values in the in-plane $\left(44.6 \mathrm{ppm} /{ }^{\circ} \mathrm{C}\right)$ and out-of-plane $\left(8.3 \mathrm{ppm} /{ }^{\circ} \mathrm{C}\right)$ directions of the nanopaper. (C,D) Thermal expansion of a single $\mathrm{CNF}$ in the temperature range of $25-100^{\circ} \mathrm{C}$. For simplification, the cross-sectional shape and length of the CNF are assumed to be a circle with a diameter 3 and $500 \mathrm{~nm}$, respectively. The dimensions at $100^{\circ} \mathrm{C}$ (the values in red) are estimated using the reported CTE values in the fiber axis $\left(6 \mathrm{ppm} /{ }^{\circ} \mathrm{C}\right)$ and cross-sectional $\left(53 \mathrm{ppm} /{ }^{\circ} \mathrm{C}\right)$ directions of the single CNF.

exhibits such marked anisotropy in thermal expansion. Attention may be required when thick nanopapers are used in electronic devices; the nanopapers only have a favorably low CTE value in the in-plane direction. The bioplastic composite containing only $2.5 \%$ CNFs also exhibited anisotropy.

\section{DATA AVAILABILITY STATEMENT}

The datasets for this article are not publicly available because the raw data supporting the conclusions of this article will be made available by the authors, without undue reservation, to any qualified researcher. Requests to access the datasets should be directed to Takayuki Hirano, Takayuki_Hirano@trc.toray.co.jp, or Tsuguyuki Saito, asaitot@mail.ecc.u-tokyo.ac.jp.

\section{AUTHOR CONTRIBUTIONS}

TH, SF, and TS designed the experiments. SI and HS prepared the samples. TH and KM performed thermal analyses. KD performed

\section{REFERENCES}

Daicho, K., Saito, T., Fujisawa, S., and Isogai, A. (2018). The crystallinity of nanocellulose: dispersion-induced disordering of the grain boundary in
XRD and FTIR analyses. MZ performed SEM observation. TH and TS mainly wrote the manuscript with the contributions of all the authors.

\section{FUNDING}

This research was in part supported by the JST-Mirai R\&D Program (JPMJMI17ED) and the JSPS Grant-in-Aid for Young Scientists (17K15298).

\section{ACKNOWLEDGMENTS}

We would like to thank Mr. Yuki Yoshida at the Toray Research Center for producing the Raman spectra of the CNF film.

\section{SUPPLEMENTARY MATERIAL}

The Supplementary Material for this article can be found online at: https://www.frontiersin.org/articles/10.3389/fchem. 2020.00068/full\#supplementary-material

biologically structured cellulose. ACS Appl. Nano Mater. 1, 5774-5785. doi: 10.1021/acsanm.8b01438

Diaz, J. A., Wu, X., Martini, A., Youngblood, J. P., and Moon, R. J. (2013). Thermal expansion of self-organized and shear-oriented cellulose 
nanocrystal films. Biomacromolecules 14, 2900-2908. doi: 10.1021/bm40 $0794 \mathrm{e}$

Diaz, J. A., Ye, Z., Wu, X., Moore, A. L., Moon, R. J., Martini, A., et al. (2014). Thermal conductivity in nanostructured films: from single cellulose nanocrystals to bulk films. Biomacromolecules 15, 4096-4101. doi: 10.1021/bm501131a

Elazzouzi-Hafraoui, S., Nishiyama, Y., Putaux, J.-L., Heux, L., Dubreuil, F., and Rochas, C. (2008). The shape and size distribution of crystalline nanoparticles prepared by acid hydrolysis of native cellulose. Biomacromolecules 9, 57-65. doi: 10.1021/bm700769p

Henriksson, M., Berglund, L. A., Isaksson, P., Lindström, T., and Nishino, T. (2008). Cellulose nanopaper structures of high toughness. Biomacromolecules 9, 1579-1585. doi: 10.1021/bm800038n

Hori, R., and Wada, M. (2005). The thermal expansion of wood cellulose crystals. Cellulose 12, 479-484. doi: 10.1007/s10570-005-5967-5

Nogi, M., Iwamoto, S., Nakagaito, A. N., and Yano, H. (2009). Optically transparent nanofiber paper. Adv. Mater. 21, 1595-1598. doi: 10.1002/adma.200803174

Soeta, H., Fujisawa, A., Saito, T., and Isogai, A. (2017). Interfacial layer thickness design for exploiting the reinforcement potential of nanocellulose in cellulose triacetate matrix. Compos. Sci. Technol. 147, 100-106. doi: 10.1016/j.compscitech.2017.05.010

Soeta, H., Lo Re, G., Masuda, A., Fujisawa, A., Saito, T., Berglund, L. A., et al. (2018). Tailoring nanocellulose-cellulose triacetate interfaces by varying the surface grafting density of poly(ethylene glycol). ACS Omega 3, 11883-11889. doi: 10.1021/acsomega.8b01616

Uetani, K., Okada, T., and Oyama, H. T. (2015). Crystallite size effect on thermal conductive properties of nonwoven nanocellulose sheets. Biomacromolecules 16, 2220-2227. doi: 10.1021/acs.biomac.5b00617
Uetani, K., Okada, T., and Oyama, H. T. (2017). In-plane anisotropic thermally conductive nanopapers by drawing bacterial cellulose hydrogels. ACS Macro Lett. 6, 345-349. doi: 10.1021/acsmacrolett.7b00087

Wada, M. (2002). Lateral thermal expansion of cellulose $\mathrm{I}_{\beta}$ and $\mathrm{III}_{\mathrm{I}}$ polymorphs. J. Polym. Sci. Part B Polym. Phys. 40, 1095-1102. doi: 10.1002/polb.10166

Wanasekara, N. D., Santos, R. P. O., Douch, C., Frollini, E., and Eichhorn, S. J. (2016). Orientation of cellulose nanocrystals in electrospun polymer fibres. J. Mater. Sci. 51, 218-227. doi: 10.1007/s10853-0159409-y

Wu, C.-N., Saito, T., Yang, Q., Fukuzumi, H., and Isogai, A. (2014). Increase in the water contact angle of composite film surfaces caused by the assembly of hydrophilic nanocellulose fibrils and nanoclay platelets. ACS Appl. Mater. Interfaces 6, 12707-12712. doi: 10.1021/am502701e

Zhao, M., Ansari, F., Takeuchi, M., Shimizu, M., Saito, T., Berglund, L. A., et al. (2018). Nematic structuring of transparent and multifunctional nanocellulose papers. Nanoscale Horiz. 3, 28-34. doi: 10.1039/c7nh00104e

Conflict of Interest: The authors declare that the research was conducted in the absence of any commercial or financial relationships that could be construed as a potential conflict of interest.

Copyright (c) 2020 Hirano, Mitsuzawa, Ishioka, Daicho, Soeta, Zhao, Takeda, Takai, Fujisawa and Saito. This is an open-access article distributed under the terms of the Creative Commons Attribution License (CC BY). The use, distribution or reproduction in other forums is permitted, provided the original author $(s)$ and the copyright owner(s) are credited and that the original publication in this journal is cited, in accordance with accepted academic practice. No use, distribution or reproduction is permitted which does not comply with these terms. 